\title{
USE OF COMPUTATIONAL FLUID DYNAMIC TO PREDICT AIRFLOW AND TEMPERATURE DISTRIBUTION IN A RESIDENTIAL BUILDING WITH AN UNDER FLOOR AIR DISTRIBUTION SYSTEM
}

\author{
${ }^{1}$ Abd Alnasser Almate A. Ali, \\ ${ }^{2}$ Ahmed Cherif Megri, ${ }^{3}$ Paul A. Dellenback and ${ }^{4}$ Yao Yu \\ ${ }^{1,3}$ Department of Mechanical Engineering, University of Wyoming, USA \\ ${ }^{2}$ Civil, Architectural and Environmental Engineering, CERT Research Center, \\ ${ }^{4}$ Department of Computational Science and Engineering, \\ North Carolina A and T State University, Greensboro, North Carolina, USA
}

Received 2014-02-01; Revised 2014-03-07; Accepted 2014-04-11

\begin{abstract}
Our objective is to demonstrate the use of Computational Fluid Dynamic (CFD) in building applications. In particular, CFD has been used for temperature and airflow predictions of building spaces conditioned using Under Floor Air Distribution (UFAD) System. The space used is an instrumented laboratory room (old daycare center) located at the University of Wyoming. The use of the CFD simulation results provides insightful analyses of the UFAD design and diffuser locations. The k- $\varepsilon$ turbulent model was employed to simulate the environment above an Under-Floor Air Distribution (UFAD) system, where the air is supplied using different configurations of several diffuser locations. Mesh generation was conducted using a pre-processor program, called GAMBIT. The CFD results were obtained using the program FLUENT and show flow and thermal patterns, using temperature and heat flux boundary conditions obtained experimentally. These boundary conditions have been used to predict the nature of convection heat transfer through studying velocity and temperature patterns. A realistic three dimensional model of the UFAD system is used for the simulation.
\end{abstract}

Keywords: Under Floor Air Distribution System, CFD, Experimental, Simulation, Residential Building

\section{INTRODUCTION}

Computational Fluid Dynamics (CFD) has enormous potential for industry in the twenty-first century. The CFD approach is becoming very useful for the design of many engineering applications, such as buildings, automobiles, aircrafts and turbines. The CFD method numerically solves a set of partial differential equations to evaluate velocity, pressure, temperature and the species concentration in fluid flow problems. The main aim of this study was to use a commercial CFD software (FLUENT) to predict both temperature and velocity distributions within a space using an Under Floor Air Distribution (UFAD) system.
Numerical investigations have been performed to predict the temperature and the velocity distributions within a conditioned single room using cooling UFAD system. The study of the vertical momentum of the supply airflow, the distance from diffuser, the orientation of the boundaries on the airflow and the temperature gradient were carried out for a three dimensional enclosure, with two supply diffusers located at the center of the room, two windows, on south and east walls and an exhaust grille.

FLUENT is a computational fluid dynamics package used to simulate flow problems. It is designed on the Finite Volume Method (FVM) to solve governing equations for a fluid. The FVM has two important

$$
\text { North Carolina A and T State University, Greensboro, North Carolina, USA }
$$


advantages that made it very useful in many computational dynamics applications. The first one, the computational domain is divided into control volumes and each volume integrals in equations that contain a divergence term are converted to surface integrals using the divergence theorem. These terms are then calculated as fluxes across volume surfaces of each finite volume, because the flux entering a given volume is identical to that leaving the adjacent volume, these methods are called conservative. The second advantage of the finite volume method is that it can be used with unstructured meshes (FI, 2003; Ismail-Zadeh and Tackley, 2010).

FLUENT has different physical models for various applications of fluid flow, such as incompressible or compressible, inviscid or viscous, laminar or turbulent, etc. Actually, FLUENT's package consists of two separate programs; GAMBIT and FLUENT. The GAMBIT is used to create and mesh the geometries of the flow, where FLUENT solves and analyzes the equations for the geometries (FI, 2003).

Our objective is to demonstrate the use of the CFD in building applications. In particular, CFD has been used for temperature and airflow predictions of building spaces conditioned using Under Floor Air Distribution (UFAD) System. The space used is an instrumented laboratory room (old daycare center) located at Laramie, WY. The k- $\varepsilon$ turbulent model was employed to simulate the environment above an Under-Floor Air Distribution (UFAD) system, where the air is supplied using different configurations of several diffuser locations.

\section{MODELING}

The governing equations of fluid dynamics, known as partial differential equations, express conservation of mass, momentum and energy. The equations equate the time rate of change of mass, momentum and energy at a point in a fluid to the source terms representing various physical mechanisms affecting the rate at which these properties change over time.

Any flow can be classified into laminar, transition or turbulence depending on the ratio of convective to viscous momentum transport (Reynolds number). In the case of laminar flow, the instantaneous value of a variable at any given position and time in space is equal to its mean value (Zhuang and $\mathrm{Li}, 2007$ ).

\subsection{Turbulence Modeling}

Turbulence modeling is an approach to investigate turbulent flows using the concept of averaging variables over time. This approach leads to having new, unknown terms in our governing equations. Thus we need additional equations to model the new unknowns.

Various turbulence models exist and (Ghila, 2003). Chen (1995), published a CFD paper, demonstrating indoor airflow simulations by various numerical turbulence models. He mentioned five different turbulence models, the standard (k- $\varepsilon$ ), a low Reynolds number $(\mathrm{k}-\varepsilon)$, a two-layer $(\mathrm{k}-\varepsilon)$, a two-scale $(\mathrm{k}-\varepsilon)$ and a renormalization group RNG $(k-\varepsilon)$ to solve the governing equations and compare their performance in predicting natural convection, forced convection and mixed convection in rooms. He found that the standard $(k-\varepsilon)$ gives good results and the RNG (k- $\varepsilon$ ) is only slightly better than the standard $(k-\varepsilon)$ for all cases. Otherwise the performance of the other models is not stable (Chen, 2007). The RNG (k- $\varepsilon$ ) provides the best performance in many engineering applications such as massive separation, vortex shedding behind bluff bodies, stall in wide-angle diffusers and room ventilation (Wang and Pepper, 2007).

\subsection{The Standard (k- $\varepsilon$ ) Model}

In 1972, Launder and Jones proposed the earliest complete two-equation turbulence model, called the standard (k- $\varepsilon$ ) Model. It is the most complete and widely used turbulent model. It includes two separate transport equations to represent the turbulent properties of a flow, the turbulent kinetic energy $\mathrm{k}$ and the turbulent dissipation rate. It is now considered the standard turbulence model (Pope, 2000; Recktenwald, 2009; Saad, 2011; Stolpa, 2004). The following transport equations of kinetic energy $\mathrm{k}$ and dissipation $\varepsilon$ are presented:

$$
\begin{gathered}
\frac{(\partial \rho \mathrm{k})}{\partial \mathrm{t}}+\frac{\left(\partial \rho \mathrm{u}_{\mathrm{i}} \mathrm{k}\right)}{\partial \mathrm{x}_{\mathrm{i}}}=\frac{\partial}{\partial \mathrm{x}_{\mathrm{j}}}\left(\Gamma_{\mathrm{k}} \frac{\partial \mathrm{k}}{\partial \mathrm{x}_{\mathrm{j}}}\right)+\left[\mathrm{P}_{\mathrm{k}}+\mathrm{P}_{\mathrm{b}}-\rho \varepsilon\right] \\
\frac{(\partial \rho \varepsilon)}{\partial \mathrm{t}}+\frac{\left(\partial \rho \mathrm{u}_{\mathrm{i}} \varepsilon\right)}{\partial \mathrm{x}_{\mathrm{i}}}=\frac{\partial}{\partial \mathrm{x}_{\mathrm{j}}}\left(\Gamma_{\varepsilon} \frac{\partial \varepsilon}{\partial \mathrm{x}_{\mathrm{j}}}\right)+\mathrm{C}_{\in 1} \mathrm{P}_{\mathrm{k}} \frac{\varepsilon}{\mathrm{k}}+\mathrm{C}_{\in 3} \mathrm{P}_{\mathrm{b}} \frac{\varepsilon}{\mathrm{k}}-\mathrm{C}_{\in 2} \rho \frac{\varepsilon^{2}}{\mathrm{k}}
\end{gathered}
$$

where, the diffusion and the production rate of turbulent kinetic energy for incompressible flow are given by:

$$
\begin{gathered}
\Gamma_{\mathrm{k}}=\mu+\frac{\mu_{\mathrm{t}}}{\sigma_{\mathrm{k}}} \\
\Gamma_{\varepsilon}=\mu+\frac{\mu_{\mathrm{t}}}{\sigma_{\varepsilon}}
\end{gathered}
$$




$$
\begin{gathered}
\mathrm{P}_{\mathrm{k}}=\mu_{\mathrm{t}}\left(\frac{\partial \mathrm{u}_{\mathrm{i}}}{\partial \mathrm{x}_{\mathrm{j}}}+\frac{\partial \mathrm{u}_{\mathrm{j}}}{\partial \mathrm{x}_{\mathrm{i}}}\right) \frac{\partial \mathrm{u}_{\mathrm{i}}}{\partial \mathrm{x}_{\mathrm{j}}} \\
\mathrm{P}_{\mathrm{b}}=\beta \mathrm{g}_{\mathrm{i}} \frac{\mu_{\mathrm{t}}}{\mathrm{P}_{\mathrm{r}_{\mathrm{t}}}}\left(\frac{\partial \mathrm{T}}{\partial \mathrm{x}_{\mathrm{j}}}\right)
\end{gathered}
$$

The objective is to solve three equations (momentum eddy diffusivity, k-equation and $\varepsilon$-equation) for the three unknowns, (Ghila, 2003; FI, 2003).

\subsection{The RNG (k- $\varepsilon$ ) Model}

For more accuracy and acceptable prediction of different turbulent flow models, the RNG model is derived from the instantaneous Navier-Stokes equations using a mathematical technique called "renormalization group method" (FI, 2003). To calculate the turbulent diffusion term, at only the specified scale in the standard (k- $\varepsilon$ ), the RNG approach results from a modified form of the $(\varepsilon)$ equation which determines the eddy viscosity mode in various scales of motion for interaction between the turbulent dissipation and the mean shear (FI, 2003).

In this study, the popular simulation model RNG (k$\varepsilon$ ) will be used to solve our governing equations in turbulent cases. The RNG (k- $\varepsilon$ ) is proposed to improve accuracy and predicts several turbulent flows such as strong streamline curvature, transitional flows and boundary layer separation (FI, 2003).

In this part, the three dimensional case of UFAD for a single room has been simulated by the commercial software FLUENT and results are presented in terms of both velocity and isothermal distributions for steady state, viscous and incompressible Newtonian fluid situation.

We investigated the air temperature and velocity profiles within a simplified three dimensions space model, conditioned using an Under Floor Air Distribution system (UFAD). The cooling system contains two supply diffusers and one exhaust grille. The numerical calculations are carried out in an empty room without any human being or mechanical activity. The simulation results are presented as contours and plots.

\section{CASE STUDIES}

\subsection{The Under Floor Air Distribution (UFAD) Cooling System}

The main purpose of using UFAD systems are (1) improved thermal comfort and health; (2) reduced energy use and; (3) improved ventilation efficiency and indoor air quality. Lin and Linden (2005) presented a quantitative study of UFAD vertical stratification distribution. A single cooling diffuser and a single heat source are located at the same level in a room with ventilated space. Their experimental and numerical results show that the flow pattern depends on the buoyancy flux of the heat source, the momentum and volume flux of the cooling diffuser (Lin and Linden, 2005).

In this study, a three dimensional enclosure space containing four floor swirl diffusers has been simulated using FLUENT. The results show velocity and temperature distributions for one half of the instrumented laboratory room for three volume rates, 30, 55 and 90 CFM. The predicted results of the velocity and temperature distributions at specified test planes were investigated. For these simulations the regions with highvelocity movement, which can lead to human discomfort, are determined as a function of the room height (Wang and Pepper, 2007).

\subsubsection{Problem Description}

The geometric configuration is a room $(4.65 \times 3.63 \times 1.98 \mathrm{~m})$ that includes two windows with the same dimensions $(1.47 \times 0.92 \mathrm{~m})$, two diffusers having the same dimensions $(0.5 \times 0.2 \mathrm{~m})$ and an exhaust grille $(0.74 \times 0.3 \mathrm{~m})$. Finally the door is assumed to be closed and its temperature value is similar to the northern wall temperature (Fig. 1). The CFD model used for this room is built to resemble the real object as closely as possible. The remaining initializing conditions (boundary conditions) are as taken from the experimentation (Meyer, 2012), Table 1. These boundary conditions have been used to predict the nature of convection heat transfer through studying velocity and temperature patterns. A realistic three dimensional model of the UFAD system is used for the simulation.

\subsubsection{Numerical Simulation}

The first step to the analysis is building the geometry that is creating and meshing a flow model in GAMBIT (pre-processing). The computational mesh model has been constructed using hexahedron cells because our geometry is cubic, so the hex grid is the most appropriate (FI, 2003). The numerical investigated grids in ( $\mathrm{x}$ and $\mathrm{y}$ ) plane is shown in Fig. 2.

In general, the accuracy of the solution depends on the integration method, the number of cells and other parameters. On the other hand, increasing the accuracy of results means increase the calculation of time, thus a balance must be struck between computational accuracy and computing cost (Ghila, 2003). 
Abd Alnasser Almate A. Ali et al. / American Journal of Engineering and Applied Sciences 7 (1): 171-184, 2014

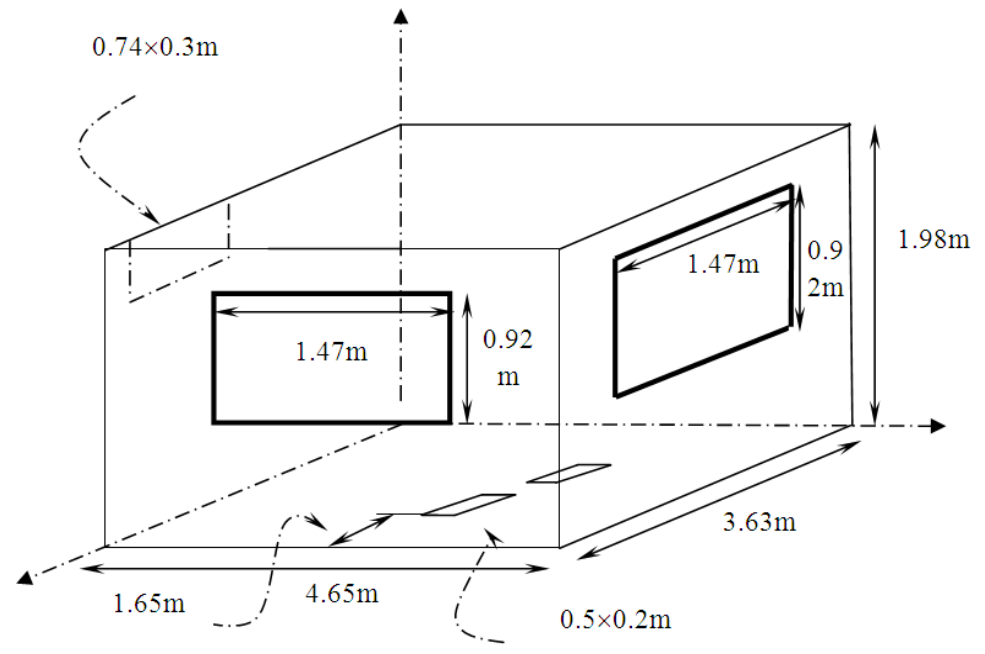

Fig. 1. The geometry and its dimensions

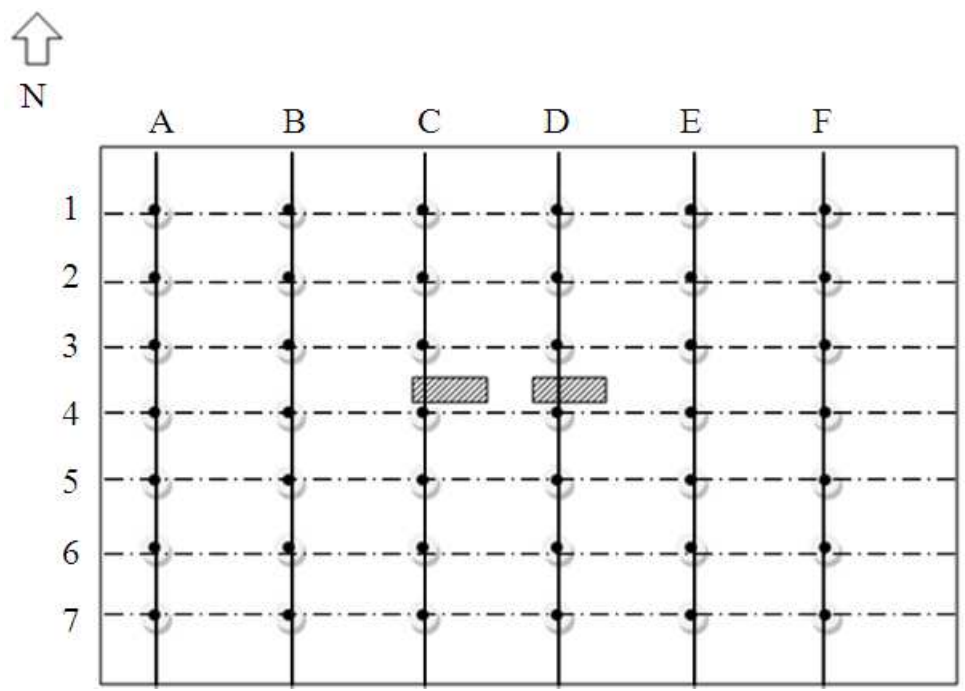

Fig. 2. The numerical investigated grids in ( $\mathrm{x}$ and $\mathrm{y})$ plane

Table 1. The boundary conditions of problem (Meyer, 2012)

\begin{tabular}{|c|c|c|c|c|}
\hline \multirow[b]{2}{*}{ \# of boundary } & \multirow[b]{2}{*}{ The boundary } & \multicolumn{3}{|c|}{ Physical type of boundary } \\
\hline & & Temperature & & Velocity \\
\hline 1 & The northern wall & $69 \mathrm{~F}$ & $293.7 \mathrm{~K}$ & 0 \\
\hline 2 & The eastern wall & $68 \mathrm{~F}$ & $293.15 \mathrm{~K}$ & 0 \\
\hline 3 & The eastern window & $72 \mathrm{~F}$ & $295.4 \mathrm{~K}$ & 0 \\
\hline 4 & The southern wall & $66 \mathrm{~F}$ & $292 \mathrm{~K}$ & 0 \\
\hline 5 & The southern window & $72 \mathrm{~F}$ & $295.4 \mathrm{~K}$ & 0 \\
\hline 6 & The western wall & $68.5 \mathrm{~F}$ & $293.4 \mathrm{~K}$ & 0 \\
\hline 7 & Ceiling & $57 \mathrm{~F}$ & $287 \mathrm{~K}$ & 0 \\
\hline 8 & Floor & $65 \mathrm{~F}$ & $293.15 \mathrm{k}$ & 0 \\
\hline 9 & Diffuser 1 & $54 \mathrm{~F}$ & $285.4 \mathrm{~K}$ & $385 \mathrm{CFM}=1.8 \mathrm{~m} \mathrm{~s}^{-1}$ \\
\hline 10 & Diffuser 2 & $55 \mathrm{~F}$ & $286 \mathrm{~K}$ & $300 \mathrm{CFM}=1.4 \mathrm{~m} \mathrm{~s} \mathrm{~s}^{-1}$ \\
\hline 11 & Vent & $62 \mathrm{~F}$ & - & - \\
\hline
\end{tabular}


The simulation results presented in this case are all based on grids consisting of about 300,000 cells. In this process, the mesh geometry has been previously created by GAMBIT will be selected in FLUENT to solve the governing equations of the flow domain numerically (processing).

Based on the supplied flow rate, the flow inside the computational domain is turbulent. For the most accurate solutions and guaranteed convergence of the indoor air ventilation, the two equation $\mathrm{RNG}(\mathrm{k}-\varepsilon)$ model is the most popular and widely used for prediction of indoor air flow patterns (Wang and Pepper, 2007).

In this study, the second order scheme to discretize the combined convective and diffusive fluxes terms across the control surface and pressure-velocity coupling with SIMPLE scheme are handled to carry out the simulation model.

\subsection{Discussions}

The post-processing for modeling the velocity and the temperature patterns has been performed to study the UFAD system of a single room.

\subsubsection{Temperature Distributions}

As simulation results, Fig. 3a-c shows the static temperature contours on various planes for the sealed building model case. A conditioned cold air comes out at cold temperature and mixes with the hot air. In this process the warm air leaves the room while the cold air settles down to the floor as its density is greater. In Fig. 3c, the southern plane shows a large warm region. The conditioned cool air from the diffuser has enough vertical momentum to reach the ceiling of the room. This air will penetrate into the warm upper region and bring warm air down into the lower region. The amount of air brought down determines the temperature in the lower region (Lin and Linden, 2005).

Since the air supply has a colder temperature than the temperature on the boundaries, there will be a temperature gradient between the supplied air from the diffusers and the boundaries. This temperature gradient depends on several factors such as the velocity of supplied air from diffusers, the distance from diffusers and the orientation of boundaries. The temperature contours also show the static temperature distribution of a plane closer to the northern wall is more uniform and colder than a plane closer to southern wall. The reason is that, the northern plane is closer to the ventilation diffuser than the southern plane, so the warm air which is located on the northern plane, closer to the northern wall, rises and exits from the upper vent faster than a plane closer to the southern wall.

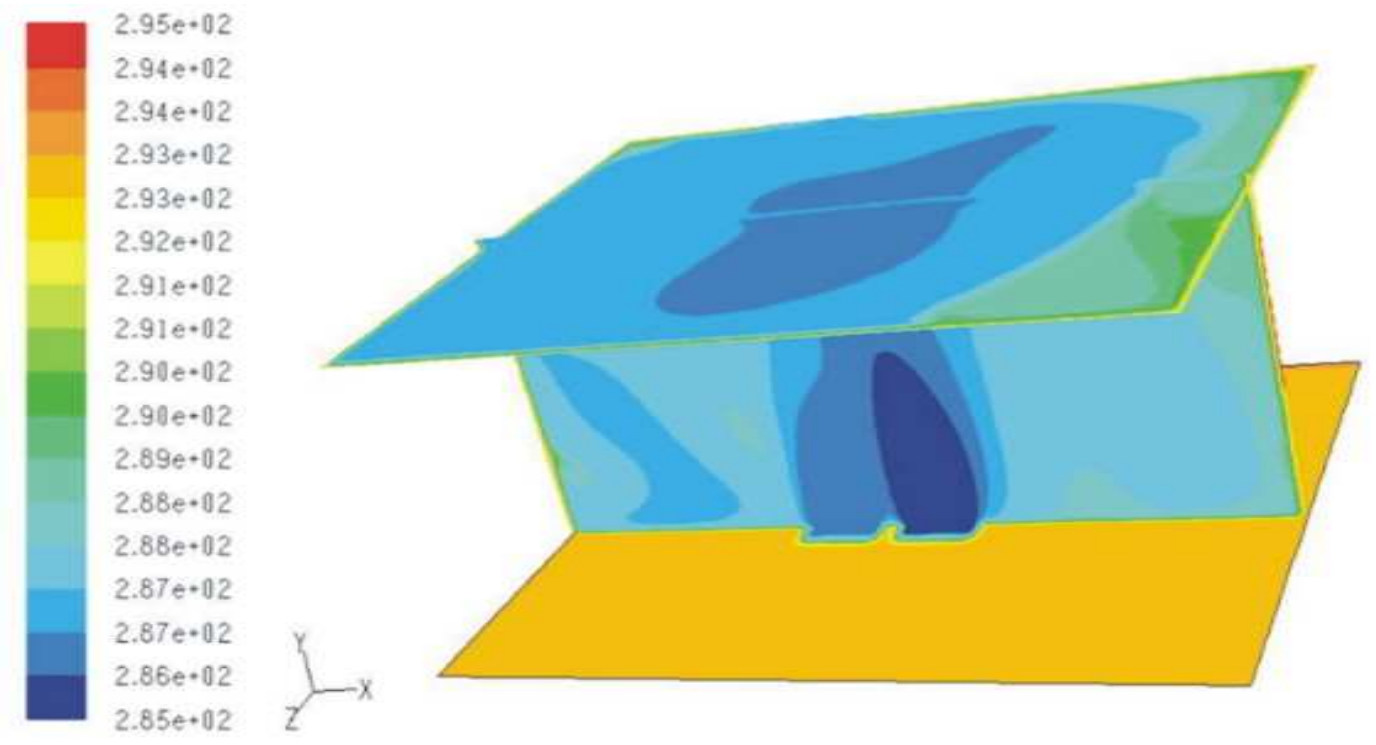

Contours of Static Temperature (k)

2012

FLUENT 6.3 (3d, dp, pbns, rke) 

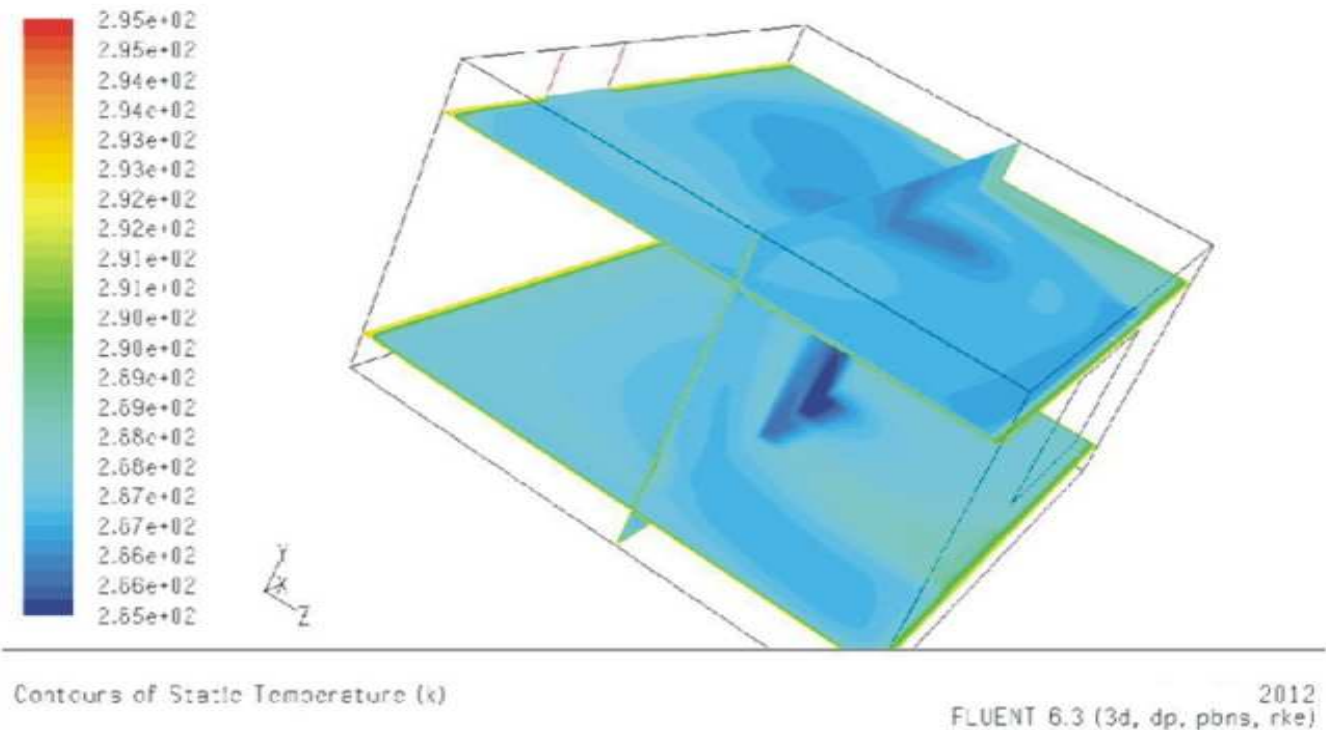

Contours of Sta:te Tenserature (k)

FLUENT 6.3 (3d, dp, pons, rke)

(b)

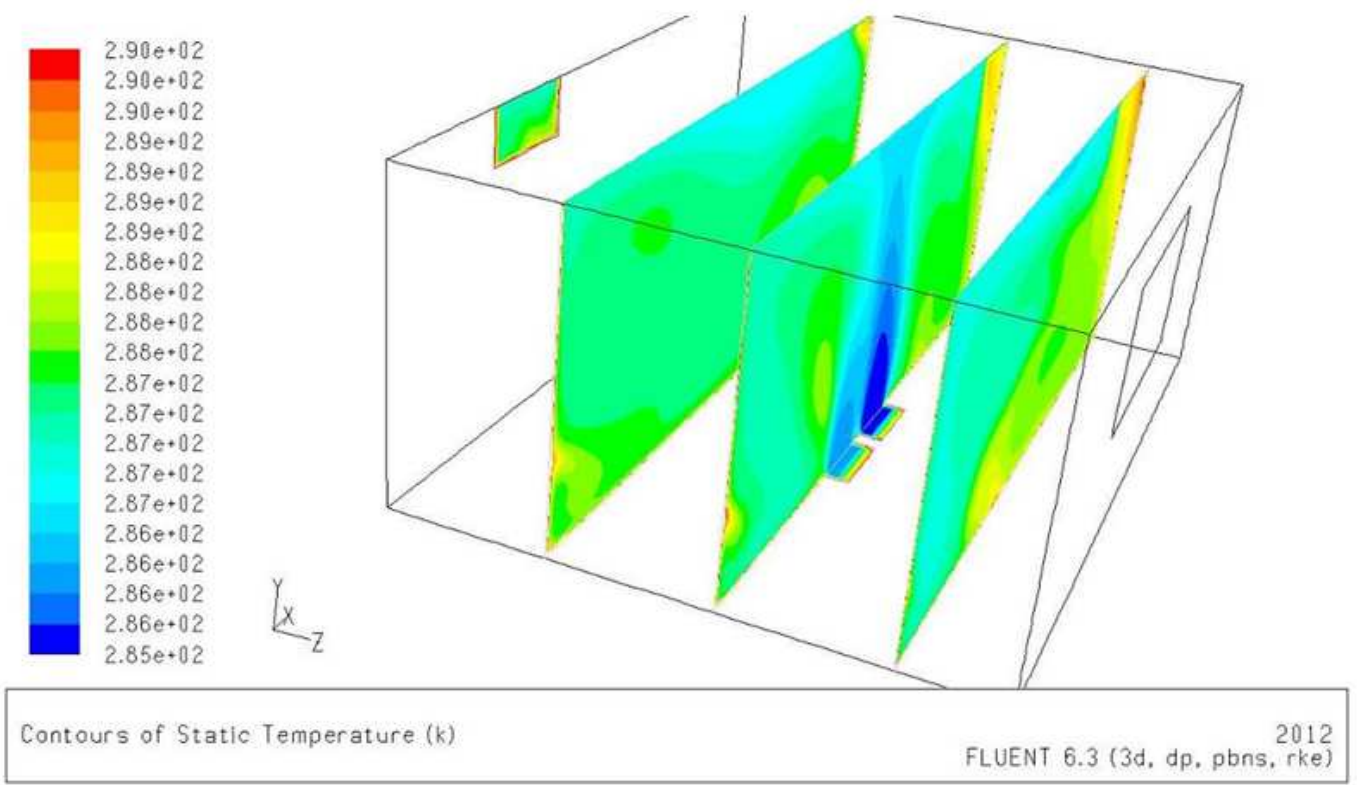

(c)

Fig. 3. (a-c) The static temperature contours on specified planes

\subsubsection{Velocity Distributions}

The diffuser's flow rate is an important factor for indoor thermal comfort. The numerical results of the velocity profiles show the velocity contours on different planes. Figure $\mathbf{4 b}$ shows the difference between the velocity distributions in two regions, one near the floor and the other at the ceiling level. The velocity gradient on the plane closer to the ceiling has higher variation than at the plane closer to the floor because while the supply air has enough vertical momentum to reach a high region, the cool air pushes the warm air and replaces it, then the gravitational force pulls the heavier, cold air down without any external forces (Lin and Linden, 2005). 
Abd Alnasser Almate A. Ali et al. / American Journal of Engineering and Applied Sciences 7 (1): 171-184, 2014
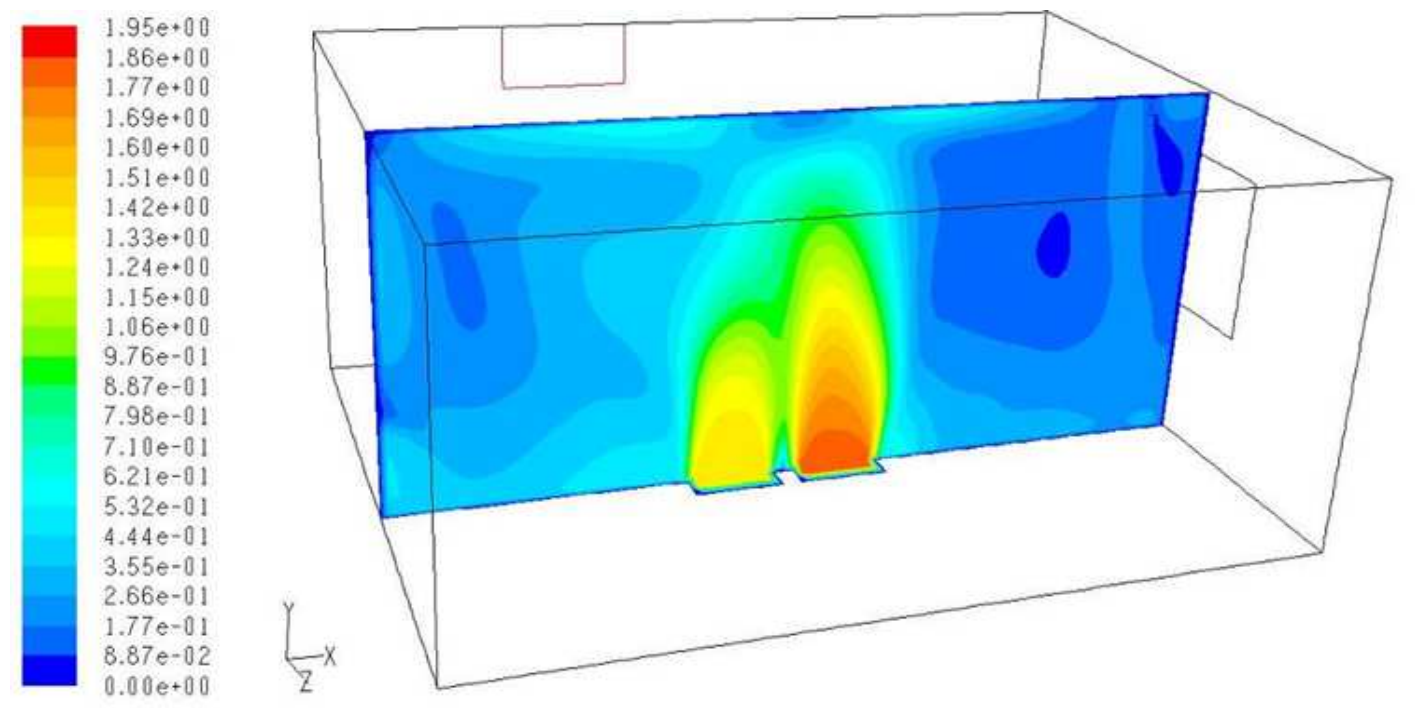

Contours of Velocity Magnitude (m/s)

2012

FLUENT 6.3 (3d, dp, pbns, rke)

(a)
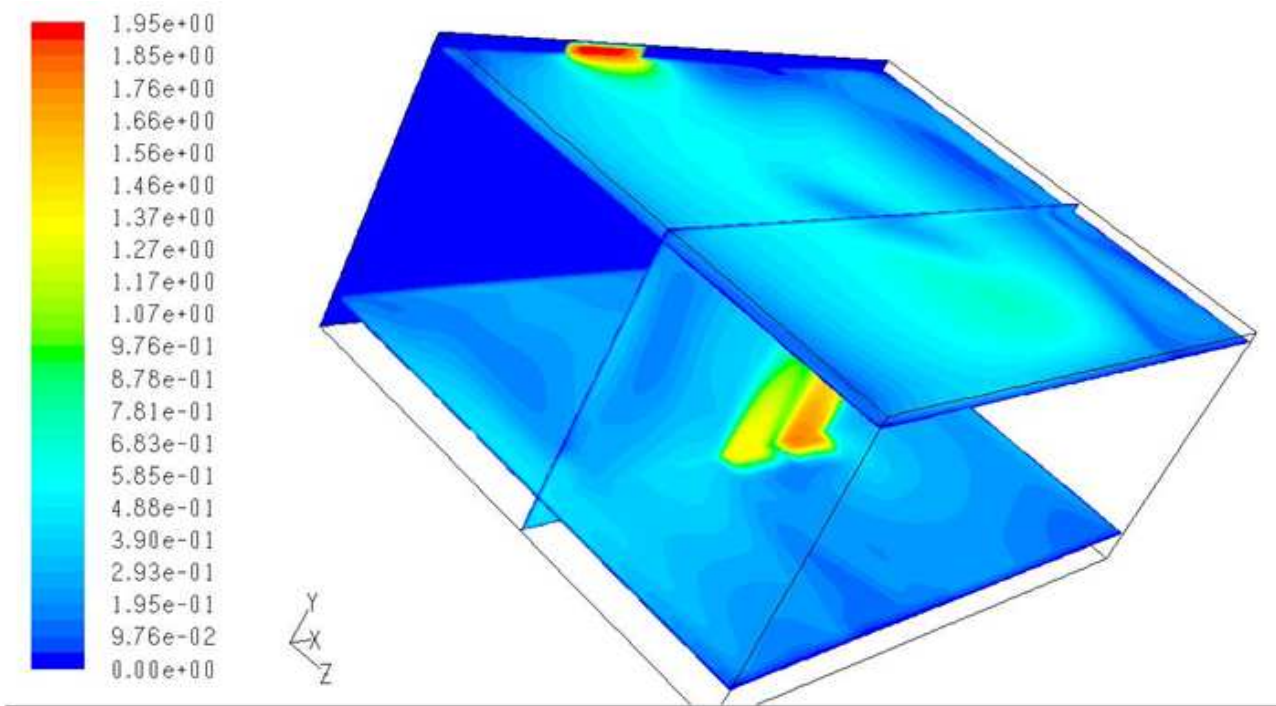

Contours of Velocity Magnitude $(\mathrm{m} / \mathrm{s})$

(b)

Fig. 4. (a and b): The velocity magnitude contours on specified planes

Hence, to provide more numerical information regarding the velocity and the temperature profiles of the space with the UFAD system, the room was divided into six vertical planes (A, B, C, D, E and F) that are perpendicular to the northern wall and seven vertical planes $(1,2,3,4,5,6$ and 7$)$ that are perpendicular to the eastern wall see (Fig. 2). The temperature profile varies as a function of the height as presented in, Fig. 5a-f. The temperature distributions along the planes (B and E) are uniform as seen in the Fig. $\mathbf{5 b}$ and $\mathbf{e .}$ 
Abd Alnasser Almate A. Ali et al. / American Journal of Engineering and Applied Sciences 7 (1): 171-184, 2014

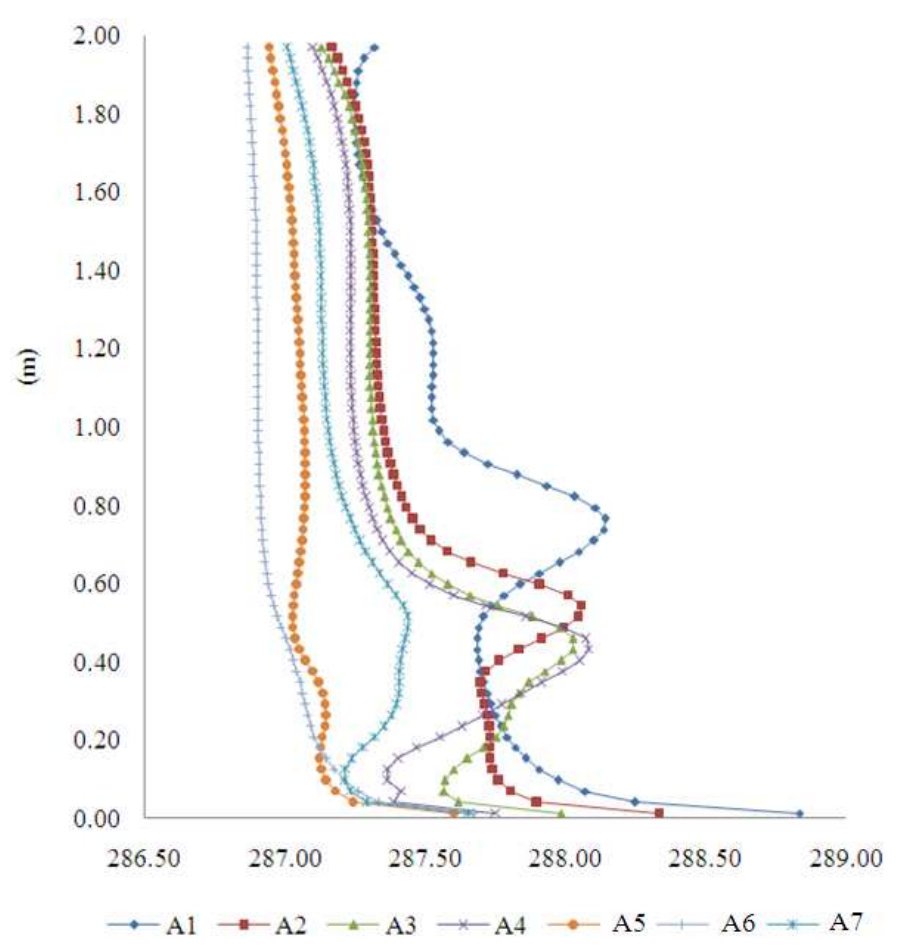

(K)

(A)

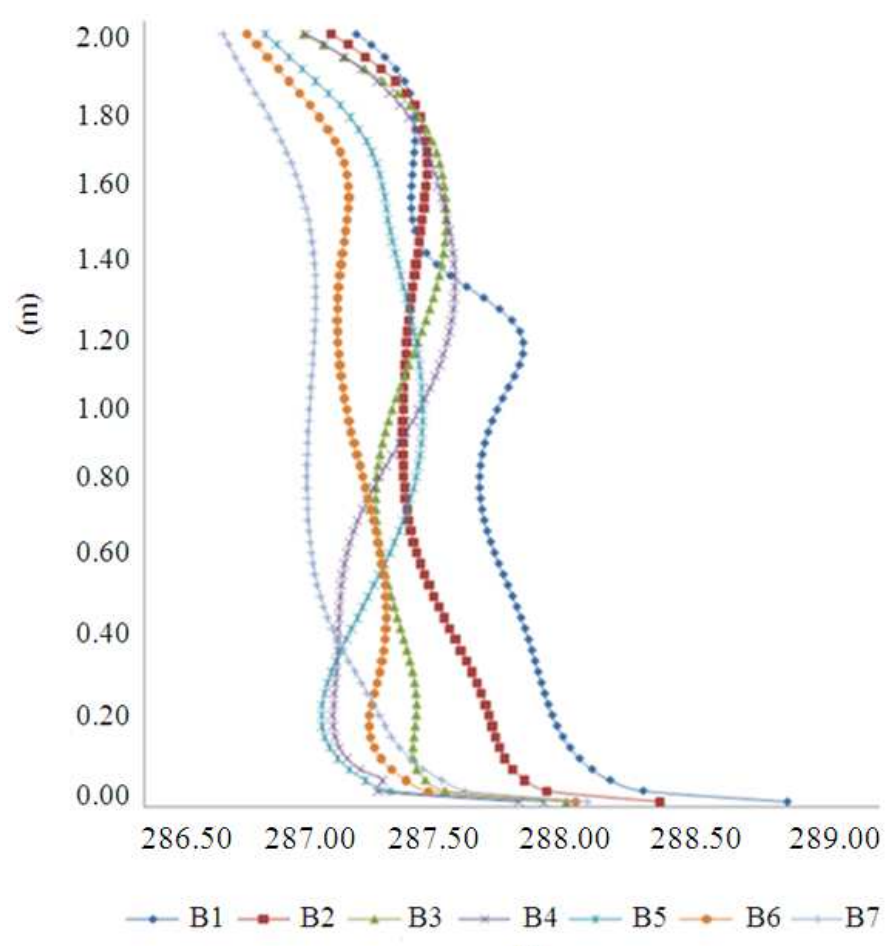

(K)

(B) 
Abd Alnasser Almate A. Ali et al. / American Journal of Engineering and Applied Sciences 7 (1): 171-184, 2014

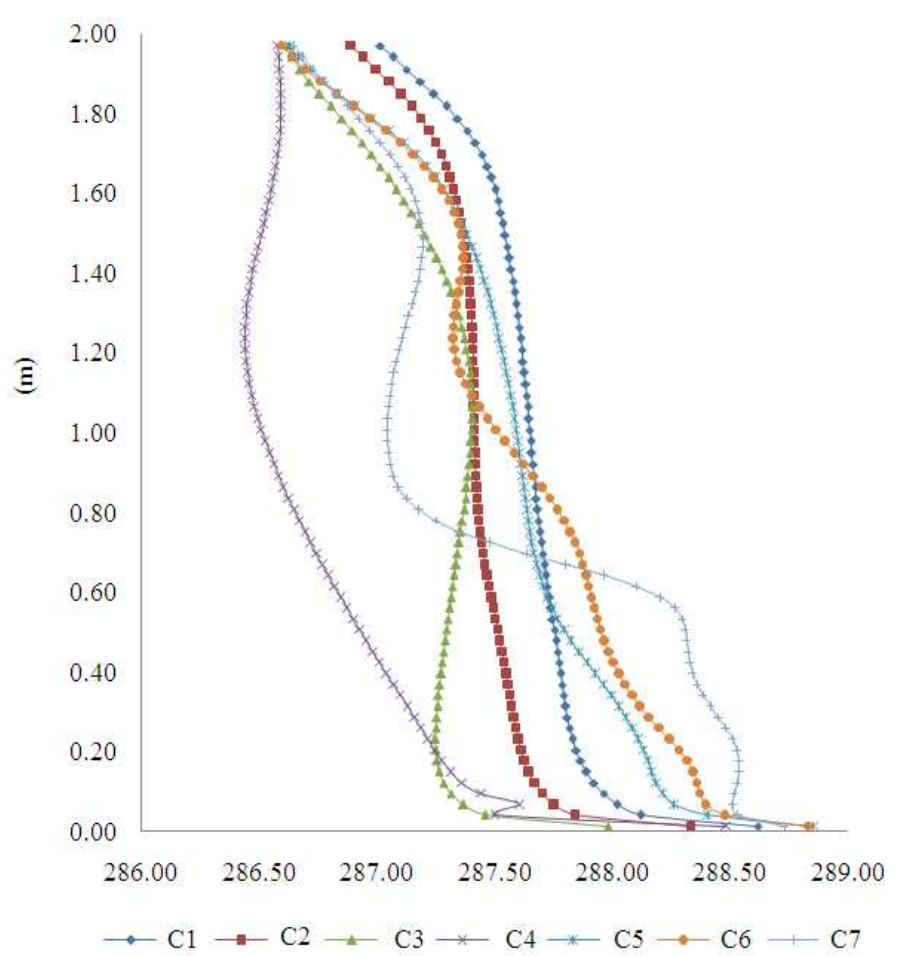

(C)

(K)

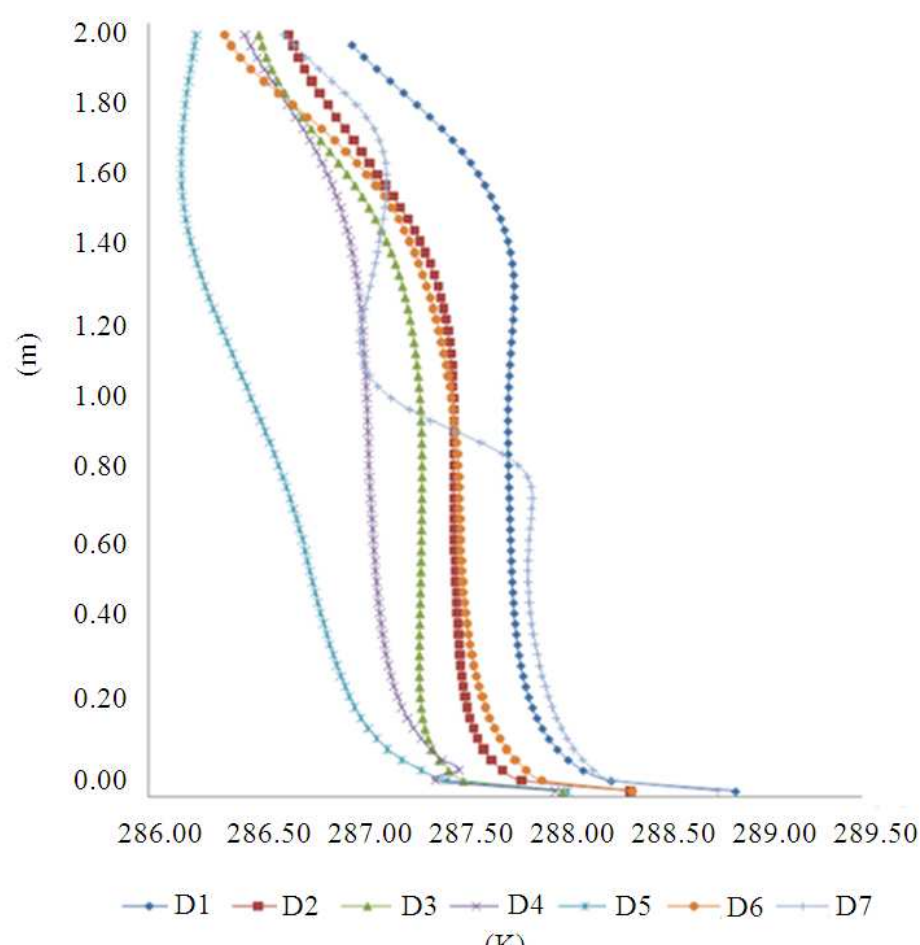

(D) 
Abd Alnasser Almate A. Ali et al. / American Journal of Engineering and Applied Sciences 7 (1): 171-184, 2014

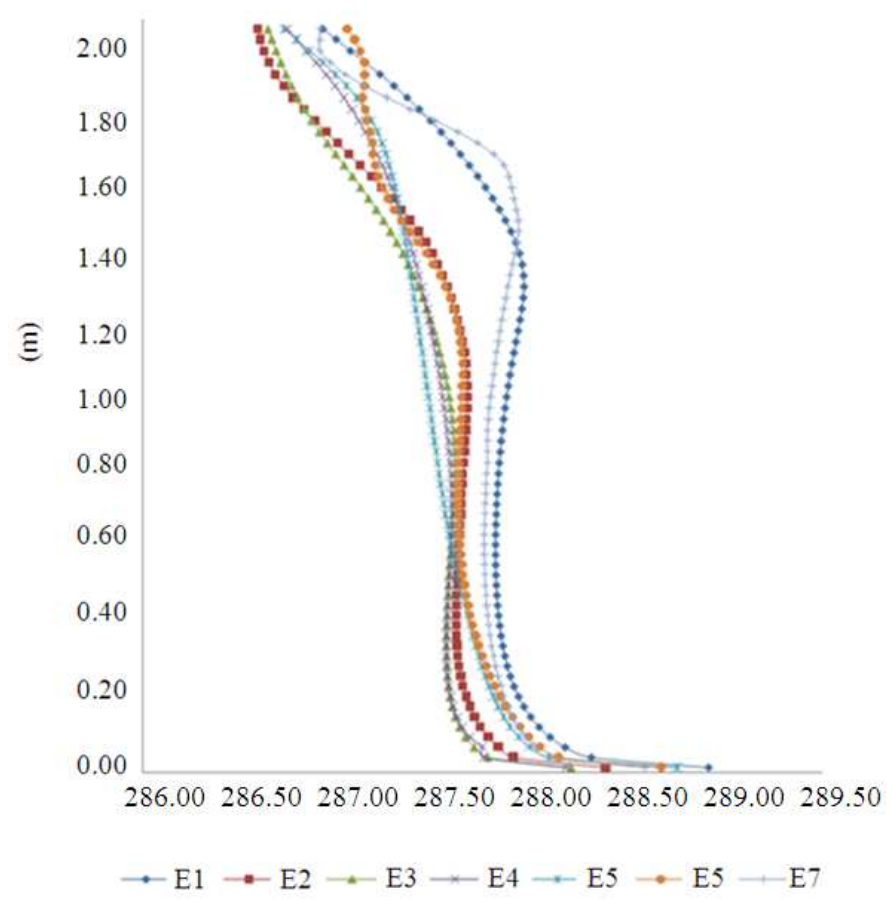

(E)

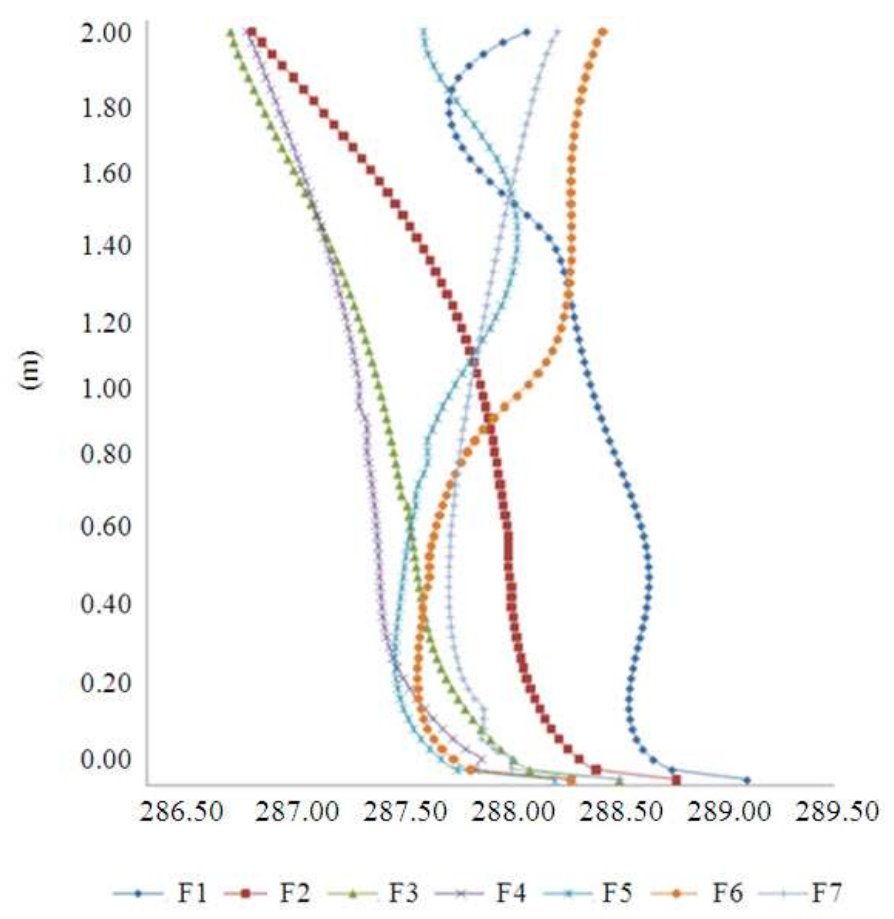

(F)

Fig. 5. (A to F): The static temperature variation at planes A, B, C, D, E and F 
Abd Alnasser Almate A. Ali et al. / American Journal of Engineering and Applied Sciences 7 (1): 171-184, 2014

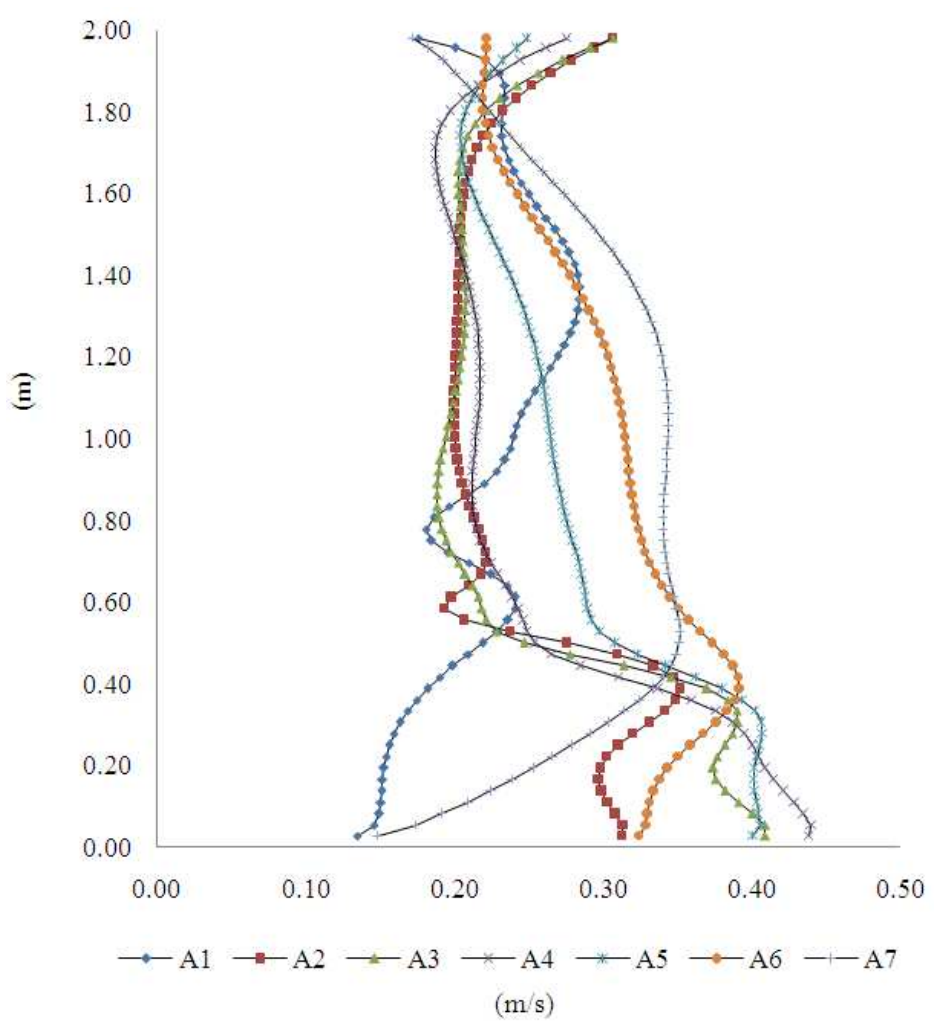

(A)

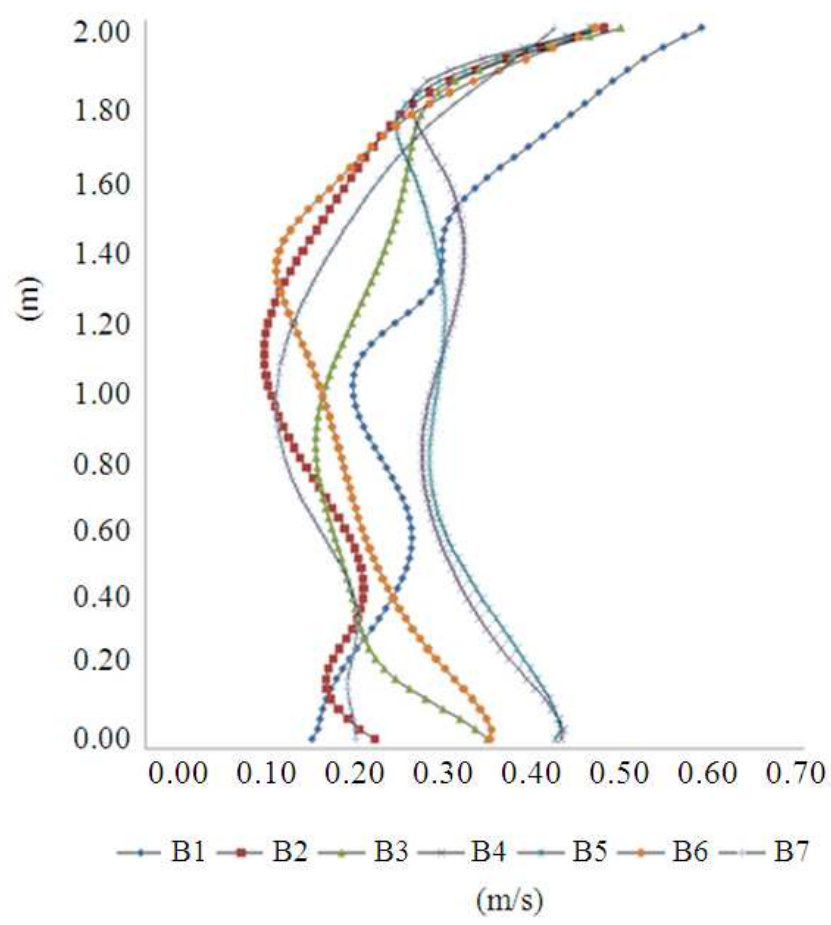

(B) 
Abd Alnasser Almate A. Ali et al. / American Journal of Engineering and Applied Sciences 7 (1): 171-184, 2014
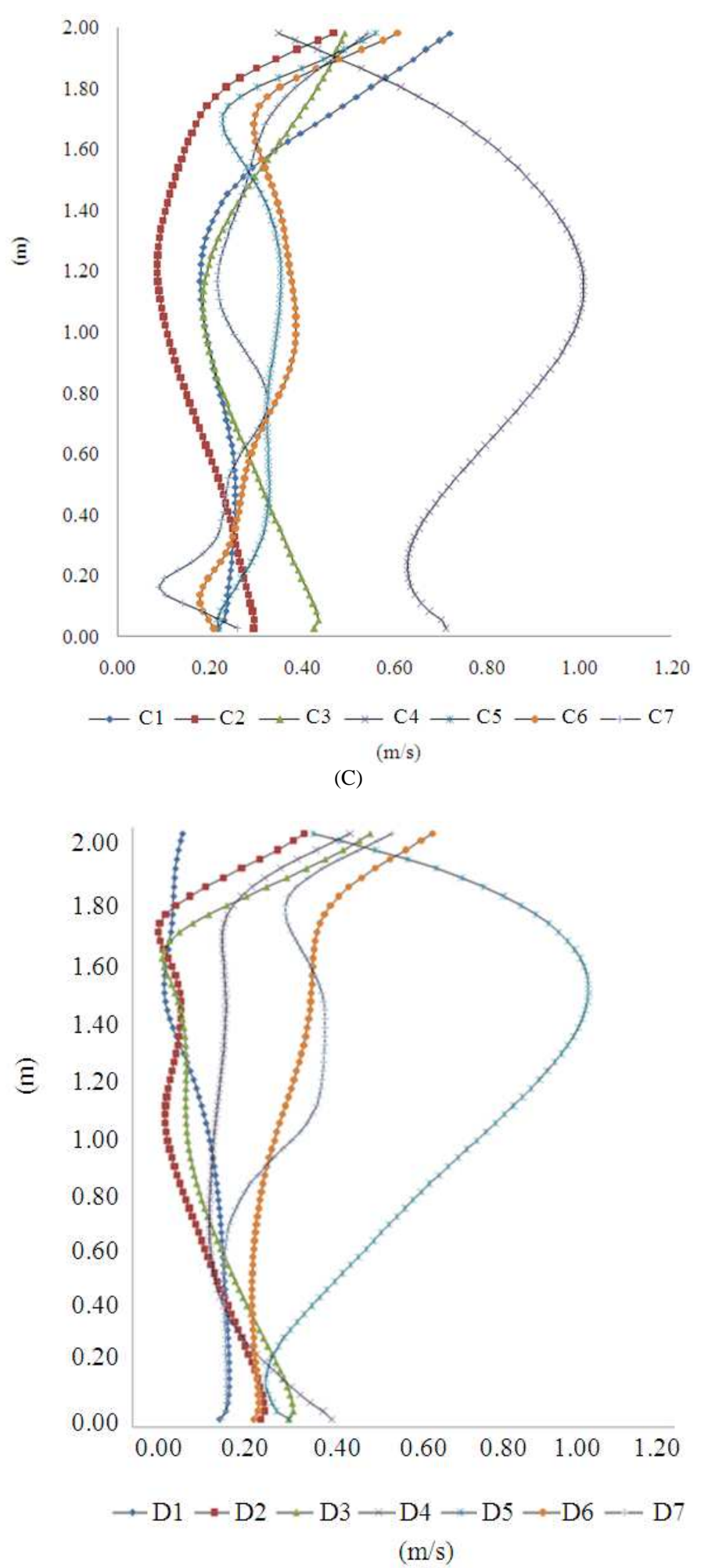

(D) 
Abd Alnasser Almate A. Ali et al. / American Journal of Engineering and Applied Sciences 7 (1): 171-184, 2014

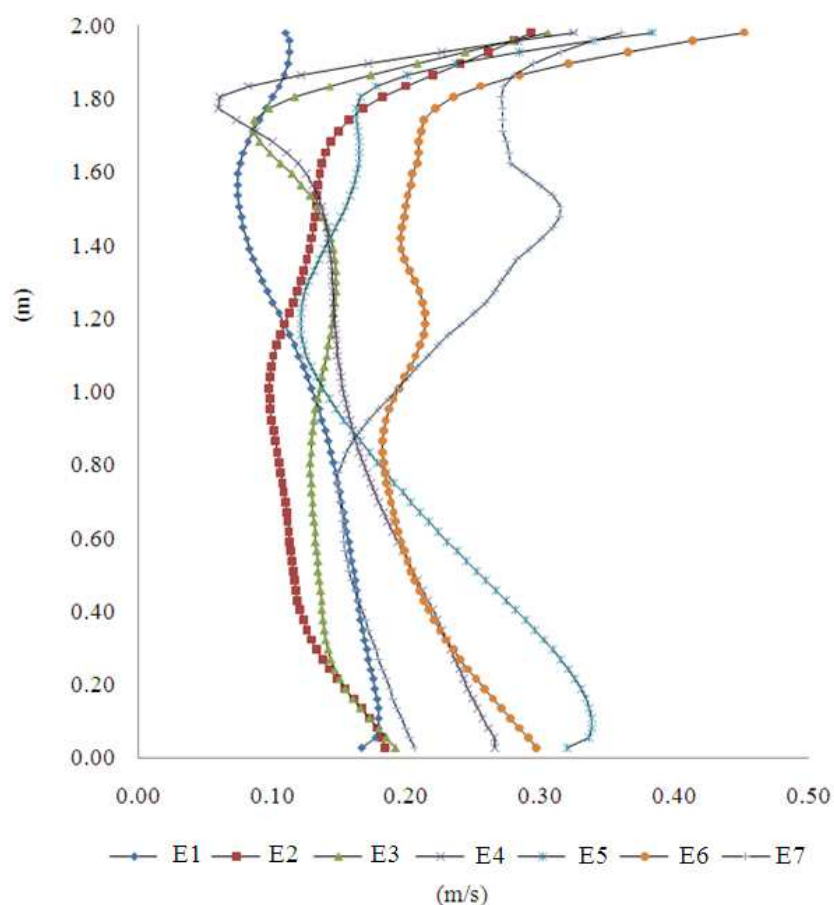

(E)

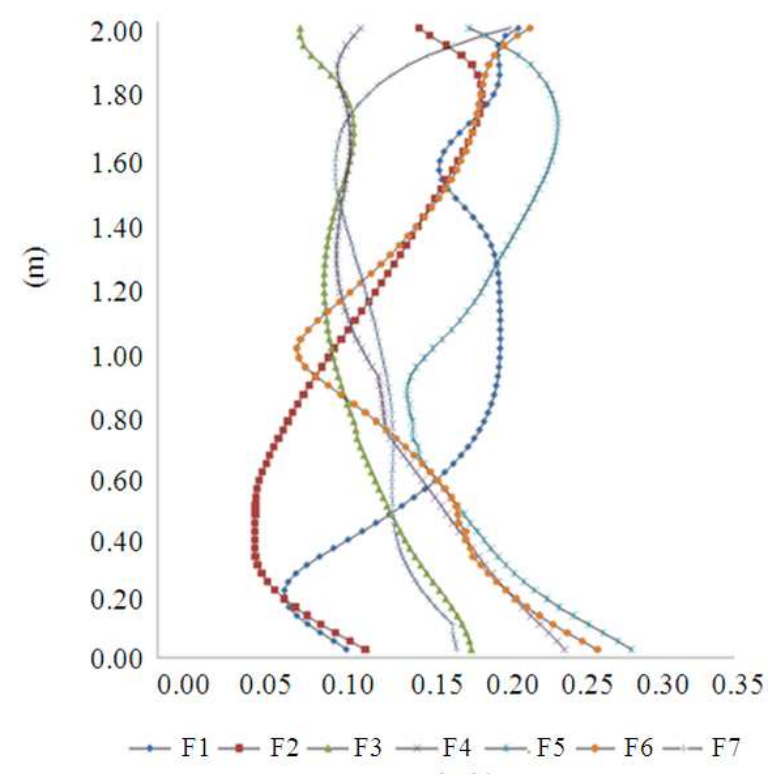

(F)

Fig. 6. (A to F): The velocity magnitude variation at planes A, B, C, D, E and F

The main reason is that planes $\mathrm{B}$ and $\mathrm{E}$ are located closely, in the middle between diffuser 1 and the western wall and diffuser 2 and the eastern wall respectively. Figure $\mathbf{5 c}$ and $\mathbf{d}$ show the static temperature profiles of the lines C4 and D5 respectively. They have the lowest values compared to other profiles on the same planes; this is due to the test planes being close to diffusers. 
The available numerical data for the velocity distribution (Fig. 6a-f) on the plane B shows that the velocity magnitude at B1 has the largest value at $2 \mathrm{~m}$ high above the floor because it is located at the front of the exhaust vent hole Fig. 6b. The largest variation is shown in the Fig. $6 c$ and d. On the planes $\mathrm{C}$ at $\mathrm{C} 4$ and D at D5 velocity profiles show values above $1 \mathrm{~m} \mathrm{~s}^{-1}$. The Fig. 6b and $\mathbf{e}$ show that the velocity profiles are more uniform than other velocity profiles in Fig. $\mathbf{6 a}, \mathbf{c}, \mathbf{d}$ and $\mathbf{f}$ because the test planes are far away from diffusers.

\section{CONCLUSION}

The steady-state simulation of an Under Floor Air Distribution (UFAD) system was investigated using the program FLUENT. Numerical investigations have been performed to predict the temperature and the velocity distributions within a conditioned single room using cooling UFAD system. The study of the vertical momentum of the supply airflow, the distance from diffuser, the orientation of the boundaries on the airflow and the temperature gradient were carried out for a three dimensional enclosure, with two supply diffusers located at the center of the room, two windows, on south and east walls and an exhaust grille.

For the UFAD case, the static temperature distribution within the space depends on the vertical momentum of supply airflow, the distance from diffusers and the orientation of the boundaries. The best location for uniform temperature distribution is at the middle distance between diffuser 1 and the western wall and diffuser 2 and the eastern wall. The velocity magnitude of the air flow at ventilation has the largest value at a location $2 \mathrm{~m}$ high because it is located in front of the exhaust vent, thus the region which is located next to the northern wall will be cooler than other locations.

\section{REFERENCES}

Chen, Q., 1995. Comparison of different k- $\varepsilon$ models for indoor air flow computations. Numerical Heat Transfer, Part B, 28: 353-369. DOI: 10.1080/10407799508928838

Chen, Q., 2007. Comoarison of different k-epsilon models for indoor air flow computations. Numerical Heat Transfer.

FI, 2003. FLUENT 6.1 Documentation. Fluent, Inc.,

Recktenwald, G., 2009. The k- $\varepsilon$ turbulence model. Department of Mechanical and Materials Engineering, Portland State University.

Ghila, A.M., 2003. Numerical investigation of recess casing treatments in axial flow fans. PhD., Thesis, Cranfield University, UK.
Ismail-Zadeh, A. and P. Tackley, 2010. Computational Methods for Geodynamics. Cambridge University Press, New York, ISBN-10: 1139489356.

Lin, Y.J.P. and P.F. Linden, 2005. A model for an under floor air distribution system. Energy Build., 37: 399409.

Meyer, R., 2012. An examination and analysis of residential applications of under floor air distribution systems using a realistic test environment and methodology to assess thermal performance for heating and cooling conditions. MSc., Thesis, University of Wyoming.

Saad, T., 2011. Turbulence modeling for beginners. University of Tennessee Space Institute.

Pope, S.B., 2000. Turbulent Flows. 1st Edn., Cambridge University Press, Cambridge, ISBN-: 0521598869, pp: 771.

Stolpa, S., 2004. Turbulent Heat Transfer. University of Notre Dame. South Bend.

Wang, X. and D.W. Pepper, 2007. Numerical simulation for under-floor air distribution system with swirl diffusers. J. Heat Transfer, 129: 589-594. DOI: 10.1115/1.2709974

Zhuang, F. and J.C. Li, 2007. New Trends in Fluid Mechanics Research. Shanghai, Springer.

\section{Nomenclature}

h Convective heat transfer $\left(\mathrm{W} / \mathrm{m}^{2} .{ }^{\circ} \mathrm{C}\right)$

$\mathrm{x}_{\mathrm{i}} \quad$ Cartesian coordinates $(\mathrm{m})$

$\mathrm{u}_{\mathrm{i}} \quad$ Velocity components $(\mathrm{m} / \mathrm{s})$

$\mathrm{T}$ Temperature $\left({ }^{\circ} \mathrm{C}\right)$

p Static Pressure $(\mathrm{Pa})$

$\rho \quad$ Density $\left(\mathrm{kg} / \mathrm{m}^{3}\right)$

$\rho_{0} \quad$ Constant density of the flow $\left(\mathrm{kg} / \mathrm{m}^{3}\right)$

$\mu \quad$ Dynamic viscosity $(\mathrm{kg} / \mathrm{ms})$

$\mathrm{v} \quad$ Kinematic viscosity $\left(\mathrm{m}^{2} / \mathrm{s}\right)$

k Thermal conductivity $\left(\mathrm{W} / \mathrm{m} .{ }^{\circ} \mathrm{C}\right)$

$\beta \quad$ Coefficient of thermal expansion $(1 / \mathrm{K})$

$\mathrm{g}_{\mathrm{j}} \quad$ Acceleration due to gravity $\left(\mathrm{m} / \mathrm{s}^{2}\right)$

$\mathrm{k} \quad$ Kinetic energy $(\mathrm{J})$

$\varepsilon \quad$ Dissipation $\left(\mathrm{m}^{2} / \mathrm{s}^{3}\right)$

$\mu^{\mathrm{t}} \quad$ Turbulent viscosity $\left(\mathrm{m}^{2} / \mathrm{s}\right)$

$\Gamma_{\mathrm{k}} \quad$ Diffusion coefficient for k-equation $\left(\mathrm{m}^{2} / \mathrm{s}\right)$

$\Gamma_{\varepsilon} \quad$ Diffusion coefficient for $\varepsilon$-equation $\left(\mathrm{m}^{2} / \mathrm{s}\right)$

$\mathrm{P}_{\mathrm{k}} \quad$ Production rate of turbulent kinetic energy (J/kg.s)

$\mathrm{P}_{\mathrm{b}} \quad$ Buoyancy force $(\mathrm{N})$

$\mathrm{G}_{\mathrm{r}} \quad$ Grashof number

$P_{\mathrm{r}} \quad$ Prandtl number

$\mathrm{P}_{\mathrm{r}_{\mathrm{t}}} \quad$ Turbulent prandtl number 